\title{
European Tobacco Products Directive (TPD): current impact and future steps
}

\author{
Constantine I Vardavas
}

School of Medicine, University of Crete, Heraklion, Greece

\section{Correspondence to} Dr Constantine I Vardavas, School of Medicine, University of Crete, Heraklion 70013, Greece; vardavas@tobcontrol.eu

Received 19 October 2021 Accepted 19 January 2022

\section{Check for updates}

(c) Author(s) (or their employer(s)) 2022. No commercial re-use. See rights and permissions. Published by BMJ.

To cite: Vardavas $\mathrm{Cl}$ Tob Control

2022:31:198-201.

\section{ABSTRACT}

Efforts to reduce the toll of tobacco-related morbidity and mortality in the European Union are spearheaded by the Tobacco Products Directive (TPD), a legal act implemented during 2016-2021, with the overall aim to reduce tobacco consumption by $2 \%$ in Europe. Within this time frame, several core tobacco control measures were implemented, the impact of which is outlined within this manuscript. Key successful legislative actions implemented in this time frame led to greater availability of information and further regulation of additives, the banning of mentholated cigarettes, enhanced pictorial package warnings and a regulatory framework for ecigarettes. While repeated cross-sectional data indicated a $12.5 \%$ relative reduction in smoking prevalence after implementation of the TPD, the differential regulation of cigarettes and roll-your-own tobacco compared with other products, such as cigarillos, e-cigarettes and heated tobacco products, may have also led to product displacement. Moreover, as the TPD could not keep up with the ever-changing nicotine product landscape, further adaptations may be needed.

Tobacco use within the European Union Member States (EU MS) has a significant impact on health and on the provision of healthcare, and poses an additional burden to economies within the Eurozone, many of which are already under substantial economic constraints due to austerity measures of the previous decade and the current impact of the COVID-19 pandemic. ${ }^{1}$ Efforts to reduce the toll of tobacco-related morbidity and mortality in the EU are spearheaded by the Tobacco Products Directive (TPD), a legal act that was designed to meet the obligations of the EU under the WHO Framework Convention for Tobacco Control (FCTC). These two instruments, the TPD and the FCTC, provide EU MS with a framework of actions and goals that aims to protect human health and potentially reduce tobacco consumption, monitor tobacco product evolution and reduce demand for tobacco products across the EU. Although significantly modified during the negotiation phase, ${ }^{2-4}$ the central legislative framework of the TPD provided substantial leverage for the implementation of tobacco control measures across countries, as collectively, the regulations proposed in the TPD could not have been achieved at the national level alone, within which industry interference and political willingness may hamper national tobacco control efforts. ${ }^{5}$

The TPD transposed into EU MS legislation and implemented during 2016-2021, aiming to reduce tobacco consumption by $2 \%$ within this time frame. ${ }^{6}$ Although a low threshold to pass in the short term, the long-term impact of the TPD was expected to be high due to the long-term effects that tobacco control policies have on youth. Within this time frame, tobacco control policies outlined in the TPD were gradually implemented across the $27 \mathrm{EU}$ MS (and the UK at that time), supported by central policy actions, European projects (such as the Joint Action on Tobacco Control) and by EU MS regulators' efforts. In light of the actions performed to date, both centrally and across the 27 EU MS, this manuscript aims to provide a short overview of the actions performed, targets that have been met and areas that warrant future effort in light of the everchanging tobacco product landscape in Europe.

\section{Increasing the evidence base on tobacco product constituents and additives}

Over the past years, we have witnessed an evolutionary maelstrom that led to the development and proliferation of new brands of existing cigarettes, e-cigarettes and heated tobacco products (HTPs), products that further perpetuate the complexity of the taxonomy, understanding and effective regulation of tobacco products and their constituents.

To support the monitoring of tobacco product design and constituents and within the context of the TPD, the European Commission migrated from a decentralised paper/CD submission process to a centralised online submission portal, the European Union Common Entry Gate (EU-CEG). The EU-CEG is an information portal through which the tobacco industry is mandated to submit the complete chemical composition and product design information for each product it wishes to market in the EU MS, which is required to make aspects of this information publicly available. Indeed, EU-CEG may be the first application of Big Data to tobacco control. It is a living database of over 220000 product versions submitted across the 27 EU MS. Each submission contains quantitative information on product design, constituents and emissions, and multiple PDFs with qualitative data.

The EU-CEG, while highly complex and challenging to use in day-to-day regulatory work at the EU MS level, is an exceptional monitoring tool as it may allow EU MS to swiftly respond to product evolutions or upcoming 'outbreaks' of newly evolved tobacco products or 'variants of interest' across the EU MS markets as they emerge. The need for such a fast turnaround and assessment of new 'variants of interest' is especially evident in light of the swift expansion of JUUL in the USA and the launch and proliferation of HTPs. ${ }^{8-11}$ However, for its maximum potential to be reached, the issue of 
ensuring sustainable staff capacity working on tobacco control in the EU MS would need to be addressed.

Preliminary analysis of EU-CEG data for tobacco products has indicated that among $12 \mathrm{EU}$ MS, and within almost 40000 tobacco product types submitted, priority additives were identified more than 90000 times-indicating the extensive appearance of these additives within tobacco products on the EU market. ${ }^{12}$ Similarly, the EU tracking and tracing system also opens the window for the use of Big Data in tobacco control as it allows for the tracking of every legal cigarette pack in the EU from the moment of production or import, up to the dispatch to the retail store. It is the only system in the world, which works across borders. However, as access to the data is restricted, its use by researchers, although promising, is still limited. ${ }^{13}$

\section{Banning menthol and other characterising flavours}

Although nicotine and its pharmacological effects are central to sustaining tobacco product use, they are insufficient to support product acceptance. ${ }^{14} 15$ Sensory stimuli attributable to flavours are particularly critical to product acceptance, reducing subjective measures of cravings and withdrawal, even in the absence of nicotine. A primary example of such an additive is menthol. Menthol is 1 of the 15 priority additives for tobacco products that were subject to further evaluation within the TPD, ${ }^{16}$ based on the data that these additives may (1) contribute to toxic, addictive or carcinogenic, mutagenic or reprotoxic properties of cigarettes and roll-your-own (RYO) tobacco, (2) may result in a characterising flavour, or (3) may facilitate inhalation or nicotine uptake. Within the course of the TPD, supporting information on these additives was requested from the industry, and the extensive data were assessed by an independent panel, the conclusions of which are expected to contribute to the regulation of tobacco product ingredients at the EU level. ${ }^{17}$

The banning of a 'mentholated' characterising flavour is hence a key aspect of the success of the TPD. From May 2016, the TPD prohibited cigarettes and RYO tobacco with characterising flavours (a flavour other than that of tobacco) from being placed on the market, with a 4-year phase-out period for products with a characterising menthol flavour (May 2020). ${ }^{18}$ This ban has significant implications. More than $90 \%$ of smokers in the EU reported the cigarette flavour as the most decisive parameter related to their brand choice, rated higher than the importance of price or packaging. ${ }^{19}$ Similarly, youth aged $15-24$ years were more likely than the older participants to report initial smoking because of menthol flavour (adjusted OR $(\mathrm{aOR})=2.4$ ) or a specific sweet, fruity or spicy flavour $(\mathrm{aOR}=2.6) .{ }^{19}$ While the tobacco industry has extensively researched the role of flavours in product acceptance in the context of product development and evolution, the assessment of flavours for regulatory purposes in tobacco control is still in its infancy. ${ }^{20}$ Consumers' perception of flavour attributes is driven by specific concentrations of individual flavour compounds, which form a composite odour, the way cigarettes are perceived by a consumer. Even though the consumer perceives these aroma constructs, the perception, recognition and identification of flavours in the human nose occur at the level of the individual chemical compounds. Similarly, the flavour and odour of tobacco, both before and during burning, comprise numerous individual flavour attributes. Each of these unique attributes arises from the impact of individual chemical compounds on the human olfactory system. Based on these principles, the TPD prohibits tobacco and RYO tobacco from conveying a characterising flavour by applying principles of sensory science to tobacco control, a significant step in tobacco product regulation-with substantial applications also for other jurisdictions across the globe. ${ }^{2122}$

\section{The introduction of more prominent warning labels and the path towards plain packaging}

Harmonising labelling and packaging rules was another critical success of the TPD. It homogenised packaging across the internal market and set the legal framework for several EU MS to pursue plain packaging. The TPD, at minimum, required larger, combined text and graphic warning labels on packaging, covering $65 \%$ of the front and the back of cigarette and RYO tobacco packs, effectively prohibiting smaller packages and included a ban on promotional and misleading elements on tobacco products and their packaging. This was an essential improvement of labelling measures compared with the previous Directive 2001/37/EC, which had only more minor text-only warnings. ${ }^{23}$ Assessments of these warnings among adult smokers in six EU MS (Germany, Greece, Hungary, Poland, Romania, Spain) reported that these had increased salience, in that they noticed the warning labels more often with over half of the smokers. Furthermore, one-third of quitters noticed at least one of the five TPD-related packet changes, while around onequarter of all respondents saw changes to health warnings, standardised openings, minimum packet unit size and the removal of Tar, Nicotine and CO (TNCO) information on packaging. ${ }^{24} 25$

Eight EU MS (including at that time the UK) went beyond the TPD's minimum labelling provisions and introduced plain packaging for tobacco products, ${ }^{26}$ leading to the development of a regional evidence base in support of plain packaging. Based on evidence from EU MS, plain packaging along with pictorial warnings appear to increase awareness of tobacco-related diseases, making warnings more salient and supporting reductions in smoking. ${ }^{27-29}$ More recent evidence also indicates that about half of the EU population supports the adoption of plain packaging, however with significant cross-country differences (ranging from $72 \%$ in Ireland and the UK, 66\% in Belgium to $28 \%$ in Portugal). ${ }^{30}$

On the contrary, while introducing pictorial warning labels across the EU for cigarettes and RYO, other products regulated under the TPD such as smokeless tobacco, waterpipe tobacco, HTPs and e-cigarettes were mandated to have text-only warnings, which was a significant improvement from the status quo.

\section{Regulating e-cigarettes and novel tobacco products}

The TPD brought forward regulatory requirements for several design and packaging parameters of e-cigarettes, including but not limited to: maximum nicotine concentrations at $20 \mathrm{mg} / \mathrm{mL}$, a maximum volume of $2 \mathrm{~mL}$ for refillable e-cigarette tanks, childresistant refill containers and the regulation/notification of the constituents of e-liquids to regulators, via EU-CEG. Implementation of child-resistant caps, tamper-proof vials and maximum refill volumes reached high levels of compliance in pre-post product studies ${ }^{31}$ —an area of significant public health relevance due to the impact of unintentional exposures among younger children in Europe ${ }^{32}$; however, variations in the declared versus measured nicotine contents were identified, indicating the need to ensure quality control in the manufacturing processes. ${ }^{33} 34$ Under the TPD, e-cigarettes were further required to implement text-only warning messages and include a leaflet containing instructions for use and contraindications. ${ }^{35}$ Among smokers and recent quitters who used cigarettes, reported noticing and reading leaflets included in the packaging of e-cigarettes 
increased significantly from before versus after implementation of the TPD.

On the contrary to e-cigarettes which had already emerged before the TPD, HTPs had not launched during the drafting of the legislation, leading to them being covered under a more general blanket of 'novel tobacco products'. As, however, their use has expanded over the years, predominantly among youth, ${ }^{9} 1130$ more comprehensive regulation may be needed. HTPs, although required to have their ingredients and emissions reported to regulators via the EU-CEG, they were exempted from the ban on characterising flavours. Furthermore, an ambiguous clause in the TPD allowed them to self-categorise themselves as either a smokeless tobacco product or a tobacco product for smoking. Naturally, manufacturers opted for the latter (defining the products as 'smokeless'), and hence HTPs were mandated to carry the smaller (30\% coverage) text-only warning labels and were not subject to stricter packaging requirements.

Despite the above, changes are likely expected to the regulation of novel tobacco products in the future as the TPD assessment report indicated that there had been problems with the TPD maintaining its relevance with novel and innovative products due to the pace at which new products have developed, ${ }^{36}$ especially taking into account that the provisions of the TPD were drafted before e-cigarettes and HTPs appeared in strength on the EU market.

\section{The overall impact of the TPD}

While a causal inference cannot be attributed solely to the implementation of the TPD, repeated cross-sectional data have indicated that smoking prevalence among those aged $15+$ years fell from $26 \%$ in 2014 to $23 \%$ in 2020 - an absolute $3 \%$ reduction in prevalence and a $12.5 \%$ relative reduction following TPD implementation, significantly higher than the target goal. ${ }^{30}$ Despite this notable drop in prevalence, the differential regulation of cigarettes and RYO tobacco compared with other smoked products (ie, cigarillos) and other products, such as e-cigarettes and HTPs, created inconsistencies concerning packaging, labelling, and flavouring and may have led to product displacement rather than a reduction in consumption, particularly among youth. ${ }^{9}$ Cohort study research has indicated that the implementation of the TPD had altered smoking behaviour through changes in consumption patterns ${ }^{37} 38$ but may also have led to product switching or displacement, which may partially explain some of the differences in prevalence for specific product categories. ${ }^{39} 40$

\section{Next steps in Europe}

The 2021 Europe's Beating Cancer Plan notes that tobacco control is placed at the centre of disease prevention efforts, with the overarching goal to create a 'tobacco-free generation'where less than $5 \%$ of the population uses tobacco-by 2040 , compared with around 25\% today. ${ }^{41}{ }^{41}$ To achieve this long-term goal, and essentially tobacco endgame in Europe, the EU has the opportunity to use drivers for change, including the potential revisions to the current TPD, revisions to the Tobacco Advertising Directive (as advertising was not a core component of the TPD), modifications to the EU Tax Directive and the recently introduced EU Green Deal's Single-Use Plastics directive, all of which will further influence both product innovation and impact population use. ${ }^{23}$ The future for tobacco control in Europe is ambitious-it remains to be seen how this momentum will be best used so as to achieve the maximum benefit to the health of the European population.
What this paper adds

- The Tobacco Products Directive (TPD) set the stage for the implementation of stricter EU wide tobacco control policies.

- The TPD increased consumer and regulator information on tobacco product additives, banned characterising flavours, regulated e-cigaretes, implemented graphic warning labels and set the stage for the implementation of plain packaging in certain European Countries.

- Although heated tobacco products were included in the TPD before their market expansion, the changing product landscape may have caused issues with the TPD maintaining its relevance with innovative and novel products - for which changes are most likely expected.

- Although product switching or displacement may partially explain some of the differrences in measured prevalence in the EU, the TPD has surpassed its initial projected goals and facilitated harmonised tobacco control measures accross the EU.

Contributors Author CIV has the sole responsibility for the submission of this manuscript.

Funding The authors have not declared a specific grant for this research from any funding agency in the public, commercial or not-for-profit sectors.

Disclaimer The content of this publication represents the views of the author only and is his sole responsibility; it cannot be considered to reflect the views of the European Commission and/or the Consumers, Health, Agriculture and Food Executive Agency or any other body of the European Union. The European Commission and the Agency do not accept any responsibility for use that may be made of the information it contains.

Competing interests CIV is the head of the Technical Group of Sensory and Chemical Assessors that assists the Independent Advisory Panel (IAP) by carrying out the practical sensory and chemical assessments of tobacco products and provides input to IAP on the methodology to be used for the technical assessment of these products.

Patient consent for publication Not required.

Ethics approval This study does not involve human participants.

Provenance and peer review Commissioned; externally peer reviewed.

\section{ORCID iD}

Constantine I Vardavas http://orcid.org/0000-0003-0171-9570

\section{REFERENCES}

1 GBD 2019 Tobacco Collaborators. Spatial, temporal, and demographic patterns in prevalence of smoking tobacco use and attributable disease burden in 204 countries and territories, 1990-2019: a systematic analysis from the global burden of disease study 2019. Lancet 2021;397:2337-60.

2 Costa H, Gilmore AB, Peeters S, et al. Quantifying the influence of the tobacco industry on EU governance: automated content analysis of the EU tobacco products directive. Tob Control 2014;23:473-8.

3 Peeters S, Costa H, Stuckler D, et al. The revision of the 2014 European tobacco products directive: an analysis of the tobacco industry's attempts to 'break the health silo'. Tob Control 2016;25:108-17.

4 Hiilamo H, Glantz SA. Old wine in new bottles: tobacco industry's submission to European Commission tobacco product directive public consultation. Health Policy 2015;119:57-65.

5 Lie JLY, Willemsen MC, de Vries NK, et al. The devil is in the detail: tobacco industry political influence in the Dutch implementation of the $2001 \mathrm{EU}$ tobacco products directive. Tob Control 2016;25:545-50.

6 TPD impact assessment report. executive summary of the impact assessment report accompanying the document proposal for a directive of the European Parliament and of the Council on the approximation of the laws, regulations and administrative provisions of the member states concerning the manufacture, presentation and sale of tobacco and related products. Available: https://ec.europa.eu/health/sites/health/files/ tobacco/docs/com 2012788 summary ia en.pdf

7 European Commission. Commission implementing decision (EU) 2015/2183 of 24 November 2015 establishing a common format for the notification of electronic 
cigarettes and refill containers. Available: https://eur-lex.europa.eu/legal-content/EN/ TXT/?uri=CELEX\%3A32015D2183

8 Cwalina SN, Leventhal AM, Barrington-Trimis JL. E-Cigarette flavour enhancers: flavoured pod attachments compatible with JUUL and other pod-based devices. Tob Control 2020;29:e127-8.

9 Laverty AA, Vardavas CI, Filippidis FT. Prevalence and reasons for use of heated tobacco products (HTP) in Europe: an analysis of Eurobarometer data in 28 countries. Lancet Reg Health Eur 2021:8:100159.

10 Lee J, Thompson LA, Salloum RG. Heated tobacco product use among US adolescents in 2019: the new tobacco risk. Tob Prev Cessat 2021;7()::1-8. January.

11 Gallus S, Lugo A, Liu X, et al. Use and awareness of heated tobacco products in Europe. J Epidemio/ 2021. doi:10.2188/jea.JE20200248. [Epub ahead of print: 16 Jan 2021].

12 Carnicer-Pont D, Tigova O, Havermans A. Tobacco products in the European Union common entry gate (EU-CEG): a tool for monitoring the EU tobacco products directive. Tobacco Prevention \& Cessation 2022;8.

13 European Commission. Systems for tobacco traceability and security features. Available: https://ec.europa.eu/health/tobacco/tracking_tracing_system_en

14 van de Nobelen S, Kienhuis AS, Talhout R. An inventory of methods for the assessment of additive increased Addictiveness of tobacco products. Nicotine Tob Res 2016;18:1546-55

15 Ahijevych K, Garrett BE. The role of menthol in cigarettes as a reinforcer of smoking behavior. Nicotine Tob Res 2010;12 Suppl 2:S110-6.

16 Commission Implementing Decision (EU) 2016/787 of 18 May 2016 laying down a priority list of additives contained in cigarettes and roll-your-own tobacco subject to enhanced reporting obligations (notified under document C(2016) 2923) (2016), 2016. Available: https://eur-lex.europa.eu/legal-content/EN/TXT/?uri=uriserv\%3AOJ. L.2016.131.01.0088.01.ENG

17 Joint Action on Tobacco Control. WP9: D9.3 report on the peer review of the enhanced reporting information on priority additives, 2020. Available: https://jaotc. eu/wp-content/uploads/2021/04/D9.3-Report-on-the-peer-review-of-the-enhancedreporting-information-on-priority-additives.pdf

18 European Network for Smoking and Tobacco Prevention. Ban on menthol cigarettes: European Union member states shall prohibit the placing on the market of tobacco products with a characterising flavour. Tob Prev Cessat 2020;6:40.

19 Laverty AA, Vardavas Cl, Filippidis FT. Design and marketing features influencing choice of e-cigarettes and tobacco in the EU. Eur J Public Health 2016;26:838-41.

20 Krüsemann EJZ, Lasschuijt MP, de Graaf C, et al. Sensory analysis of characterising flavours: evaluating tobacco product odours using an expert panel. Tob Control 2019;28:152-60.

21 European Commission. Methodology for the technical assessment of test products assisting in determining tobacco products with a characterising flavour. Application to cigarettes and roll your own products., 2020. Available: https://ec.europa.eu/health/ sites/default/files/tobacco/docs/methodology_technical-assessment_test-products_en. pdf

22 Przewoźniak K, Kyriakos CN, Hiscock R, et al. Effects of and challenges to bans on menthol and other flavors in tobacco products. Tob Prev Cessat 2021;7:1-3.

23 European Commission. Directive 2001/37/EC of the European Parliament and of the Council of 5 June 2001 on the approximation of the laws, regulations and administrative provisions of the member states concerning the manufacture, presentation and sale of tobacco products - Commission statement, 2001. Available: https://eur-lex.europa.eu/legal-content/en/ALL/?uri=CELEX\%3A32001L0037

24 Kahnert S, Driezen P, Balmford J, et al. Effectiveness of tobacco warning labels before and after implementation of the European tobacco products Directivefindings from the longitudinal EUREST-PLUS ITC Europe surveys. Eur J Public Health 2020;30:iii84-90.

25 Kyriakos CN, Driezen P, Girvalaki C, et al. Awareness and correlates of noticing changes to cigarette packaging design after implementation of the European tobacco products directive: findings from the EUREST-PLUS ITC Europe surveys. Eur J Public Health 2020:30:iii98-107.

26 Cohen JE, Zhou S, Goodchild M, et al. Plain packaging of tobacco products: lessons for the next round of implementing countries. Tob Induc Dis 2020;18:1-3.

27 Opazo Breton M, Britton J, Brown J, et al. Was the implementation of standardised tobacco packaging legislation in England associated with changes in smoking prevalence? A segmented regression analysis between 2006 and 2019. Tob Control 2021. doi:10.1136/tobaccocontrol-2021-056694. [Epub ahead of print: 29 Jul 2021].

28 Moodie C, Angus K, Stead M. Consumer response to standardized tobacco packaging in the United Kingdom: a synthesis of evidence from two systematic reviews. Risk Manag Healthc Policy 2021;14:1465-80.

29 European Commission,. Directorate-General for Health and Food Safety, Support study to the report on the application of Directive 2014/40/EU : final report, Publications Office, 2021. Available: https://data.europa.eu/doi/10.2875/161406

30 European Commission. Special Eurobarometer 506 - Attitudes of Europeans towards tobacco and electronic cigarettes. Reports and Datasets. Available: https://data. europa.eu/data/datasets/s2240_506_eng?locale=en

31 Girvalaki C, Vardavas A, Tzatzarakis M, et al. Compliance of e-cigarette refill liquids with regulations on labelling, packaging and technical design characteristics in nine European member states. Tob Control 2020;29:531.

32 Vardavas $\mathrm{Cl}$, Girvalaki C, Odani S, et al. Profile of incidental exposures to e-cigarette liquids in Europe, 2018-2019. Hum Exp Toxicol 2021:40:1045-50.

33 Girvalaki C, Tzatzarakis M, Vardavas A, et al. Discrepancies in reported versus measured nicotine content of e-cigarette refill liquids across nine European countries before and after the implementation of the EU Tobacco Products Directive. Eur Respir J 2020;55. doi:10.1183/13993003.00941-2019. [Epub ahead of print: 2002 2020].

34 Barhdadi S, Moens G, Canfyn M, et al. Impact of the revised European tobacco product directive on the quality of e-cigarette refill liquids in Belgium. Nicotine Tob Res 2021:23:227-34

35 Nikitara K, Girvalaki C, Kyriakos CN, et al. Changes in electronic cigarette use and label awareness among smokers before and after the European tobacco products directive implementation in six European countries: findings from the EUREST-PLUS ITC Europe surveys. Eur J Public Health 2020:30:iii62-7.

36 European Commission. Report from the Commission to the European Parliament the Council, the European economic and social Committee and the Committee of the regions on the application of directive 2014/40/EU concerning the manufacture, presentation and sale of tobacco and related products, 2021. Available: https://eur-lex.europa.eu/legal-content/EN/TXT/?uri=COM:2021:249: FIN

37 Zatoński M, Herbeć A, Zatoński W, et al. Cessation behaviours among smokers of menthol and flavoured cigarettes following the implementation of the EU tobacco products directive: findings from the EUREST-PLUS ITC Europe surveys. Eur J Public Health 2020;30:iii34-7.

38 Girvalaki C, Filippidis FT, Kyriakos CN, et al. Perceptions, predictors of and motivation for quitting among smokers from six European countries from 2016 to 2018: findings from EUREST-PLUS ITC Europe surveys. Int J Environ Res Public Health 2020;17. doi:10.3390/ijerph17176263. [Epub ahead of print: 2808 2020]

39 Vardavas $\mathrm{Cl}$, Kyriakos CN, Driezen $\mathrm{P}$, et al. Transitions in product use during the implementation of the European tobacco products directive: cohort study findings from the EUREST-PLUS ITC Europe surveys. Eur J Public Health 2020;30:iii10-17.

40 Filippidis FT, Driezen P, Kyriakos CN, et al. Transitions from and to roll-your-own tobacco, perceptions and health beliefs among smokers: findings from the EURESTPLUS ITC Europe surveys. Eur J Public Health 2020;30:iii18-25.

41 European Commission. communication from the commission to the European parliament and the council. Europe's Beating Cancer Plan. Available: https://ec. europa.eu/health/sites/default/files/non_communicable_diseases/docs/eu_cancerplan_en.pdf 